\title{
EXPRESSION OF GLYPICAN-3(GPC-3) AND 8-HYDROXYDEOXYGUANOSINE (8- OHDG) IN CHRONIC HEPATITIS C AND RELATIONSHIP WITH HEPATOCELLULAR CARCINOMA
}

\author{
El-Alfy Y, El-Kashishy K, George M, Abdel-Wahab M \\ *Pathology Department, Faculty of Medicine, Zagazig University
}

\begin{abstract}
Background: In Egypt, hepatocellular carcinoma (HCC) is the second most common cancer in men and the 6th most common cancer in women. Egypt has the highest prevalence of $\mathrm{HCV}$ in the world and the prevalence of HCC is increasing in the last years. Glypican-3 (GPC-3), a member of heparin sulfate proteoglycans, plays a role in cell growth, differentiation, and migration. 8-Hydroxydeoxyguanosine $(8-\mathrm{OHdG})$ is an oxidatively modified promutagenic DNA that is produced by oxygen radicals and is recognized as a useful marker in estimating DNA damage induced by oxidative stress.

The aim: This study was conducted to evaluate glypican-3 (GPC-3) and 8-hydroxydeoxyguanosine (8-OHdG) expression in chronic hepatitis $\mathrm{C}$ and hepatocellular carcinoma as predictive markers for hepatocellular carcinoma.

Methods: 75 cases (50 cases of chronic hepatitis $\mathrm{C}$ and 25 of hepatocellular carcinoma) were examined immunohistochemically using antibodies against Glypican-3 (GPC-3) and 8-Hydroxydeoxyguanosine (8-OHdG).

Results: Glypican-3 expression was observed in $18 \%$ of cases of chronic hepatitis $\mathrm{C}$, all positive cases were in the high grade, while none of low grade chronic hepatitis cases showed glypican-3 positivity. Glypican-3 expression was observed in $88 \%$ of cases of HCC. High 8-OHdG index was observed in $72.4 \%$ of cases of low grade chronic hepatitis and $95.2 \%$ of cases of high grade chronic hepatitis, while low index was observed in $27.6 \%$ of low grade chronic hepatitis and in $4.8 \%$ of cases of high grade chronic hepatitis. There was a statistically significant difference in 8 -OHdG expression between low and high grade chronic hepatitis $(\mathrm{P}=0.05)$. There was no statistically significant difference in glypican-3 and 8-OHdG expression between different grades of HCC.

Conclusion: Glypican-3 was expressed in $18 \%$ of cases of chronic hepatitis C, $35.1 \%$ of cirrhosis and $36.4 \%$ of cirrhosis adjacent to hepatocellular carcinoma. Our results suggest that GPC-3 may be considered as an early marker of liver carcinogenesis. 8-OHdG was observed in all cases of chronic hepatitis $\mathrm{C}$, with high labeling index in $82 \%$ of cases and low index in $18 \%$ of cases. Our study showed high labeling index of $8-\mathrm{OHdG}$ in $52 \%$ of cases of HCC. These results indicate that oxidative DNA damage is common in livers with chronic injury suggesting a possible link between chronic inflammation and hepatocarcinogenesis.

Key words. Glypican-3(GPC-3), 8-Hydroxydeoxyguanosine (8-OHdG), Chronic hepatitis C, Hepatocellular carcinoma, Immunohistochemistry.
\end{abstract}

\section{INTRODUCTION}

I n Egypt, hepatocellular carcinoma (HCC) is the second most common cancer in men and the $6^{\text {th }}$ most common cancer in women [1]. Egypt has the highest prevalence of $\mathrm{HCV}$ in the world and the prevalence of $\mathrm{HCC}$ is increasing in the last years [2].

Nowadays, HCV infection and its complications are among the leading public health challenges in Egypt with $13.8 \%$ of population infected [3] and in these patients, the risk of HCC is increased 17-fold [4].

Glypican-3 (GPC-3) is a member of heparin sulfate proteoglycan family which is linked to cell surface. It plays an important role in regulation of cell growth, differentiation, and migration. It is normally expressed in fetal liver and placenta but not in normal adult liver tissue [5].

Data have demonstrated a high incidence of GPC-3 expression in HCC and suggested its implication in detecting malignant hepatic lesions and it is widely recognized as an efficient serological and histochemical marker for early hepatocellular carcinoma $[6,7]$.
However, GPC-3 expression can also be detected in a variable percentage of benign liver tissue with active hepatitis, regenerative nodules and high-grade dysplastic nodules $[\mathbf{6 , 8 , 9}]$.

8 -Hydroxydeoxyguanosine $(8-\mathrm{OHdG})$ is an oxidatively modified promutagenic DNA that is produced by oxygen radicals and is recognized as a useful marker in estimating DNA damage induced by oxidative stress [10]. 8Hydroxydeoxyguanosine is one of the most widely used oxidative stress biomarkers, mainly because of its abundance in DNA and also because of its reliable detectability [11].

In patients with chronic hepatitis $\mathrm{C}$, increased 8-OHdG in DNA extracted from liver tissue was reported [12]. Studies have shown that high expression of 8-OHdG in livers with chronic hepatitis $\mathrm{C}$ predicted the development of primary HCC $[\mathbf{1 3 , 1 4}]$ as free radical production is increased at the site of inflammation, resulting in lipid peroxidation and oxidative DNA damage, which are risk factors for HCC suggesting the association of $8-\mathrm{OHdG}$ and carcinogenesis in livers with chronic hepatitis $C$ [15]. 


\section{MATERIAL AND METHODS}

This work is a retrospective, cross -sectional study carried out on 75 liver paraffin blocks that were previously diagnosed as chronic hepatitis $\mathrm{C}$ (50 cases) and hepatocellular carcinoma (25 cases), collected from the Pathology Department, Faculty of Medicine, Zagazig University, National Cancer Institute in Egypt and liver cancer institute in Menofeya, in the period from October 2012 to January 2014. The selected specimens were obtained by needle biopsy and surgical excision.

The clinical data concerning age and sex were obtained from the patients files.

Paraffin blocks of all cases were sectioned at 3-5 micron thickness and stained with routine hematoxylin and eosin stain to re-evaluate and confirm the diagnosis.

A) The histological criteria of HCV were assessed according to METAVIR system [16].

B) HCC cases were graded into well, moderately and poorly differentiated according to $\mathrm{WHO}$ [17].

The inclusion and exclusion criteria used in the current study were: 1) All cases of hepatocellular carcinoma were on top of chronic hepatitis $\mathrm{C}$ and cirrhosis. 2) pathological diagnosis of hepatocellular lesions consistent with histological diagnostic criteria of WHO. 3) Chronic hepatitis $\mathrm{B}$, alcoholic hepatitis and autoimmune hepatitis were excluded. 4)fragmented core biopsies or core biopsies containing less than 6 portal tracts were excluded.

\section{Histopathologic examination:}

The 50 cases of chronic hepatitis $\mathrm{C}$ included 29 cases low grade chronic hepatitis (A1) and 21 cases high grade chronic hepatitis ( 9 cases A2 and 12 cases A3). 15 cases were cirrhotic.

The 25 HCC cases included 9 cases well differentiated (Grade I), 11 moderately differentiated (Grade II) and 5 poorly differentiated(Grade III). Among them, 22 cases showed cirrhosis in the non neoplastic liver tissue. Immunohistochemical staining:

Immunohistochemical staining was carried out using the streptavidin-biotin immunoperoxidase technique (Dako- Cytomation, Glostrup, Denmark). Sections of 3-5 mm thickness were cut from formalin-fixed, paraffinembedded blocks, mounted on positively charged slides, deparaffinized in xylene, and rehydrated in graded alcohol. Sections were boiled in citrate buffer ( $\mathrm{pH} \mathrm{6.0)} \mathrm{for} 20$ minutes and then washed in PBS ( $\mathrm{pH}$ 7.3). Thereafter, blocking of endogenous peroxidase activity with $6 \% \mathrm{H}_{2} \mathrm{O}_{2}$ in methanol was carried out. The slides were then incubated overnight with monoclonal antibodies: Glypican3(GPC-3): Mouse monoclonal antibody, Dilution 1:100; (CM396, A,B, Clone IG12, Biocare Medical LLC, Concord, USA); 8Hydroxydeoxyguanosine(8-OHdG): Monoclonal antibody, Dilution1:100 (Clone15A3, SC-66036, Santa Cruz, California, USA). Incubation with a secondary antibody and product visualization were performed (Dako-Cytomation) with diaminobenzidine substrate (Research Genetics, Huntsville, Alabama, USA) as the chromogen. The slides were finally counterstained with Mayer's hematoxylin (BioGenex Laboratories, San Ramon, California, USA) and washed once each with distilled water and PBS. Positive and negative controls were stained at the same staining setting with the studied cases: Hepatocellular carcinoma and Chronic hepatitis C were used as positive control for glypican-3 and 8 -OHdG respectively, while negative controls were done using the same tissue with omission of the primary antibody.

\section{Evaluation of the results of immunohistochemical staining: 1- Glypican-3 immunostaining:}

The GPC-3 staining was considered positive when the granular brown reaction was found in the cytoplasm and/or the membranes. Immunoreactivity was determined semiquantitatively by examining fields (magnification, x200). Using a (0-3+) scale, the staining was described as 0 staining (negative), $1+$ staining ( $<10 \%$ of cells), $2+$ staining $(10 \%-25 \%$ of cells), or $3+$ staining $(>25 \%$ of cells) [18].

\section{2 -8-Hydroxydeoxyguanosine:}

The number of 8 -OhdG stained hepatocytes (nuclear stain) in 10 random fields (magnification, $\mathrm{x} 400$ ) was counted. The percentage of positively stained cells was calculated, which was termed the 8-OHdG label index (LI), in each field and graded as follow: low, LI <50\%; high, LI >50\% [15].

The slides were evaluated by three different pathologists working separately. All discrepancies were discussed and consensus reached.

\section{Statistical analysis:}

Statistical analysis was performed using SPSS software (SPSS, Chicago, IL, USA). Data were expressed as mean $\pm \mathrm{SD}$ for quantitative variables. For categorical variables Fisher's exact test or chi-square was used. P-value less than 0.05 was considered significant.

\section{RESULTS}

The age of the studied cases of chronic hepatitis $C$ ranged from (28-62) and the mean was $40.3 \pm 6.8$ year. The majority of studied cases of chronic hepatitis $\mathrm{C}$ were below 39 years (48\%). 
The age of the studied cases of HCC ranged from (41-73) and the mean was 57.4 \pm 8.1. The majority of studied cases of HCC were between 50-59 $(44 \%)$

Glypican-3 expression was observed in $18 \%$ of cases of chronic hepatitis $\mathrm{C}$, all positive cases were in the high grade (42.9\%), while none of low grade chronic hepatitis cases showed glypican-3 positivity. There was a statistically significant difference in glypican-3 expression between low and high grade chronic hepatitis $\mathrm{C}(\mathrm{P}=0.0016)$ (Table 1, Fig. 1).

Glypican-3 expression was observed in $88 \%$ of $\mathrm{HCC}$ cases $(77.7 \%$ of well differentiated $\mathrm{HCC}$, $100 \%$ of moderately differentiated HCC and in $80 \%$ of poorly differentiated HCC). There was no statistically significant difference in glypican-3 expression among different grades (Table 2, Fig. 2).

High 8-OHdG index was detected in $72.4 \%$ of cases of low grade chronic hepatitis and 95.2\% of cases of high grade chronic hepatitis, while low index was detected in $27.6 \%$ of low grade chronic hepatitis and in $4.8 \%$ of cases of high grade chronic hepatitis. There was a statistically significant difference in $8-\mathrm{OHdG}$ expression between low and high grade chronic hepatitis $\mathrm{C}$ $(\mathrm{P}=0.05)$ (Table 3, Fig. 3).

High 8-OHdG index was observed in $52 \%$ of cases of HCC while low index was observed in $48 \%$ of cases. There was no statistically significant difference in 8 -OHdG expression between different grades of HCC $(\mathrm{P}=0.83)$ (Table 4, Fig. 4)

Table (1): Immunoreactivity pattern of GPC-3 in chronic hepatitis $\mathrm{C}$ according to grade:

\section{Chronic hepatitis C GPC-3 immunoreactivity}

\begin{tabular}{|c|c|c|c|c|c|c|c|c|c|c|c|c|c|}
\hline & \multirow{4}{*}{ No } & \multirow{3}{*}{\multicolumn{2}{|c|}{$\begin{array}{c}\text { Negative } \\
(0)\end{array}$}} & \multirow{2}{*}{\multicolumn{6}{|c|}{ Positive }} & \multirow{3}{*}{\multicolumn{2}{|c|}{$\begin{array}{c}\text { Total } \\
\text { Positive } \\
\end{array}$}} & \multirow{4}{*}{$\mathbf{X}^{2}$} & \multirow{4}{*}{$\mathbf{P}$} \\
\hline & & & & & & & & & & & & & \\
\hline & & & & \multicolumn{2}{|c|}{$(+)$} & \multicolumn{2}{|c|}{$(++)$} & \multicolumn{2}{|c|}{$(+++)$} & & & & \\
\hline & & No & $\%$ & No & $\%$ & No & $\%$ & No & $\%$ & No & $\%$ & & \\
\hline Low grade hepatitis & 29 & 29 & 100 & 0 & 0.0 & 0 & 0.0 & 0 & 0.0 & 0 & 0.0 & 5.16 & 00 \\
\hline High grade hepatitis & 21 & 12 & 57.1 & 5 & 23.8 & 2 & 9.5 & 2 & 9.5 & 9 & 42.9 & 10 & 0.1 \\
\hline Total & 50 & 41 & 82.0 & 5 & 10.0 & 2 & 4.0 & 2 & 4.0 & 9 & 18.0 & & \\
\hline
\end{tabular}

* Significant $(\mathrm{P}<0.05)$.

Table (2) : Immunoreactivity pattern of GPC-3 in heptocellular carcinoma :

Heptocellular GPC-3 immunoreactivity

carcinoma

\begin{tabular}{|c|c|c|c|c|c|c|c|c|c|}
\hline \multirow{3}{*}{ No } & Negative & \multicolumn{6}{|c|}{ Positive expression } & \multirow{2}{*}{$\begin{array}{c}\text { Total } \\
\text { Positive }\end{array}$} & \multirow[t]{3}{*}{$\overline{X^{2}}$} \\
\hline & $(\mathbf{0})$ & & & & & & & & \\
\hline & No & No & $\%$ & No & $\%$ & No & $\%$ & $\mathrm{No}$ & \\
\hline
\end{tabular}

\begin{tabular}{llllllllllllll}
\hline Well differentiated HCC & 9 & 2 & 22.2 & 4 & 44.4 & 2 & 22.2 & 1 & 11.1 & 7 & 77.7 & 6.01 & 0.11
\end{tabular}

(Grade I)

Moderately

\begin{tabular}{lllllllllllllll}
\hline differentiated & HCC & 11 & 0 & 0.0 & 1 & 9.0 & 5 & 45.5 & 5 & 45.5 & 11 & 100.0 & 6.4 & 0.09
\end{tabular}

(Grade II)

\begin{tabular}{lccccccccccccc}
\hline $\begin{array}{l}\text { Poorly differentiated } \\
\text { HCC (Grade III) }\end{array}$ & 5 & 1 & 20.0 & 1 & 20.0 & 1 & 20.0 & 2 & 40.0 & 4 & 80.0 & 0.7 & 0.85 \\
\hline Total & 25 & 3 & 12.0 & 6 & 24.0 & 8 & 32.0 & 8 & 32.0 & 22 & 88.0 & & \\
\hline
\end{tabular}

Table (3): Immunoreactivity pattern of 8-OHdG in chronic hepatitis C:

\begin{tabular}{|c|c|c|c|c|c|c|c|}
\hline \multirow[t]{2}{*}{ Chronic hepatitis C } & \multirow[t]{2}{*}{ No } & \multicolumn{2}{|c|}{$\begin{array}{c}\text { Low index of 8-OHdG } \\
\text { expression }\end{array}$} & \multicolumn{2}{|c|}{$\begin{array}{c}\begin{array}{c}\text { High index of 8-OHdG } \\
\text { expression }\end{array} \\
\end{array}$} & \multirow[t]{2}{*}{$\mathbf{X}^{2}$} & \multirow[t]{2}{*}{$\mathbf{P}$} \\
\hline & & No & $\%$ & No & $\%$ & & \\
\hline Low grade hepatitis & 29 & 8 & 27.6 & 21 & 72.4 & \multirow{2}{*}{4.2} & \multirow{2}{*}{$0.05^{*}$} \\
\hline High grade hepatitis & 21 & 1 & 4.8 & 20 & 95.2 & & \\
\hline Total & 50 & 9 & 18 & 41 & 82 & & \\
\hline
\end{tabular}

* Significant $(\mathrm{P}=0.05)$. 
Table (4): Immunoreactivity pattern of 8-OHdG in heptocellular carcinoma:

\begin{tabular}{|c|c|c|c|c|c|c|c|}
\hline \multirow{2}{*}{\multicolumn{2}{|c|}{ Heptocellular carcinoma No }} & \multicolumn{2}{|c|}{$\begin{array}{c}\text { Low index of 8-OHdG } \\
\text { expression }\end{array}$} & \multicolumn{2}{|c|}{$\begin{array}{c}\text { High index of 8-OHdG } \\
\text { expression }\end{array}$} & \multirow[t]{2}{*}{$\mathbf{X}^{2}$} & \multirow[t]{2}{*}{$\mathbf{P}$} \\
\hline & & No & $\%$ & No & $\%$ & & \\
\hline $\begin{array}{l}\text { Well differentiated HCC } \\
\text { (Grade I) }\end{array}$ & 9 & 5 & 55.6 & 4 & 44.5 & 0.02 & 0.88 \\
\hline $\begin{array}{l}\text { Moderately differentiated } \\
\text { HCC (Grade II) }\end{array}$ & 11 & 5 & 44.5 & 6 & 54.5 & 0.05 & 0.82 \\
\hline $\begin{array}{l}\text { Poorly differentiated HCC } \\
\text { (Grade III) }\end{array}$ & 5 & 2 & 40 & 3 & 60 & 0.01 & 0.9 \\
\hline Total & 25 & 12 & $48 \%$ & 13 & $52 \%$ & & \\
\hline
\end{tabular}

$\mathrm{X}^{2}=0.36 \quad \mathrm{P}=0.83$

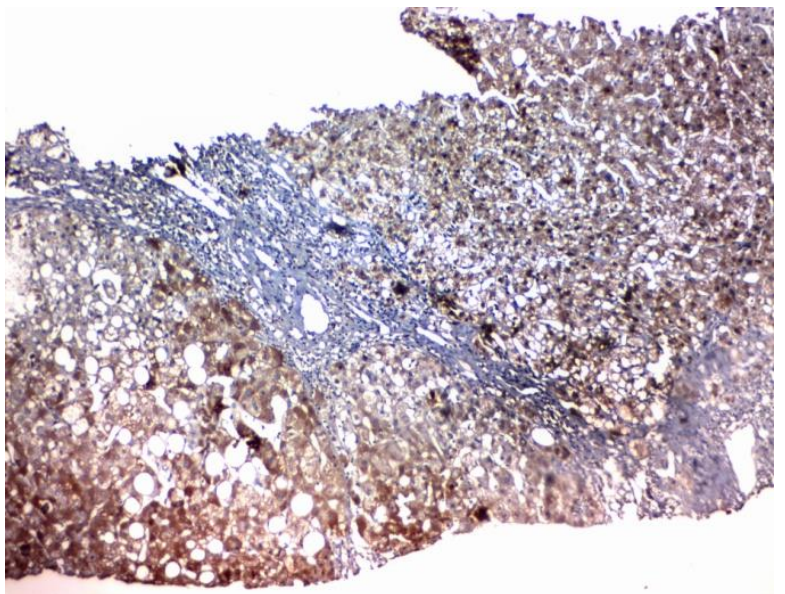

(A)

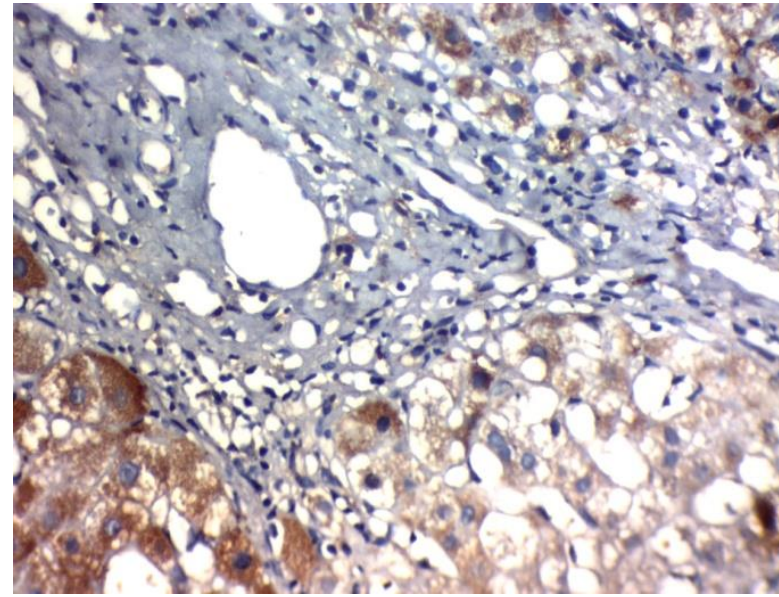

(B)

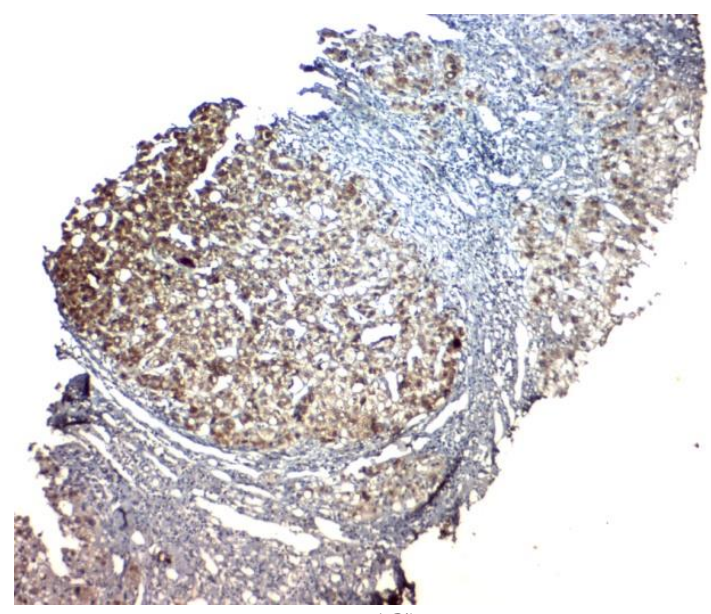

(C)

Fig. 1: Glypican-3 immunoreactivity in chronic hepatitis C:

a- A core needle biopsy of chronic hepatitis C ( A2, F3) showing positive glypican-3 cytoplasmic immunoreactivity (Score 3+) (Immunoperoxidase stain, X 200).

b- Higher magnification of previous image showing positive glypican-3 cytoplasmic immunoreactivity (Score 3+) (Immunoperoxidase stain, X 400).

c- A core needle biopsy of chronic hepatitis C (A3, F4) showing positive glypican-3 cytoplasmic immunoreactivity (Score 3+) (Immunoperoxidase stain, X 100). 


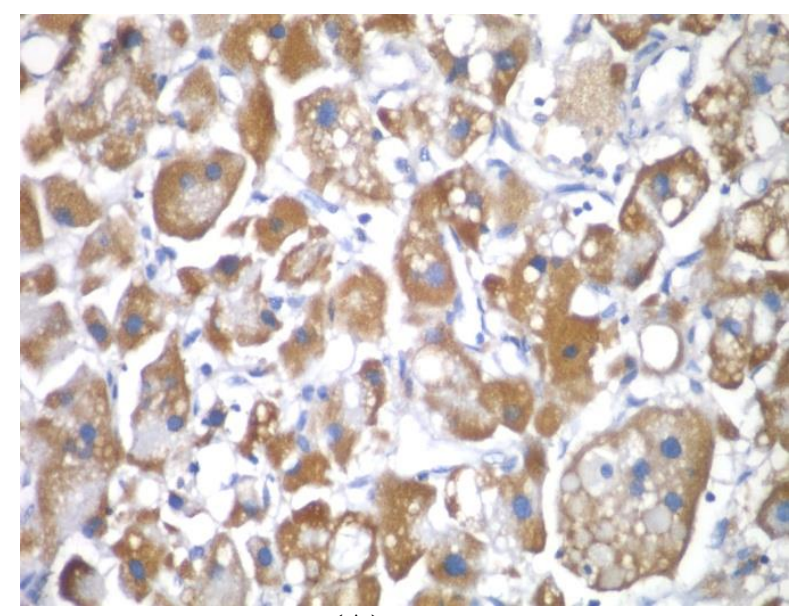

(A)

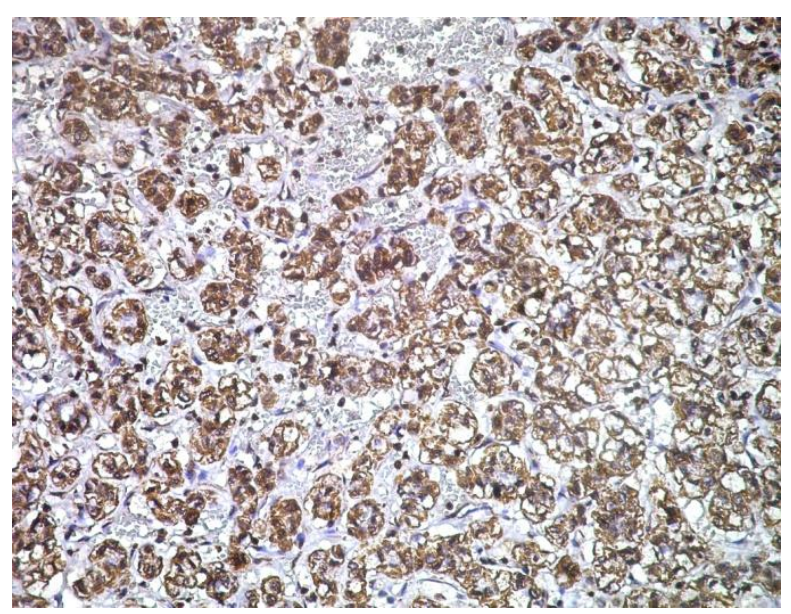

(B)

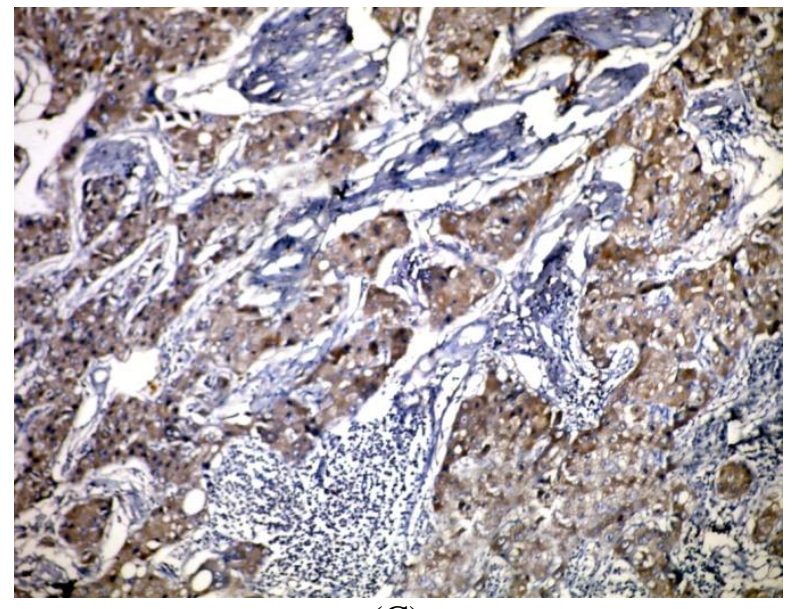

(C)

Fig. 2: Glypican-3 immunoreactivity in hepatocellular carcinoma:

a- Well differentiated HCC showing positive glypican-3 cytoplasmic immunoreactivity (score $3+$ )(Immunoperoxidase stain, $\mathrm{X} 400$ ).

b- Moderately differentiated HCC (Clear cell type) showing positive glypican-3 membranous immunoreactivity (score 3+) (Immunoperoxidase stain, X 200 ).

c- Poorly differentiated HCC showing positive glypican-3 cytoplasmic immunoreactivity (score $3+$ )(Immunoperoxidase stain, X 300 ). 


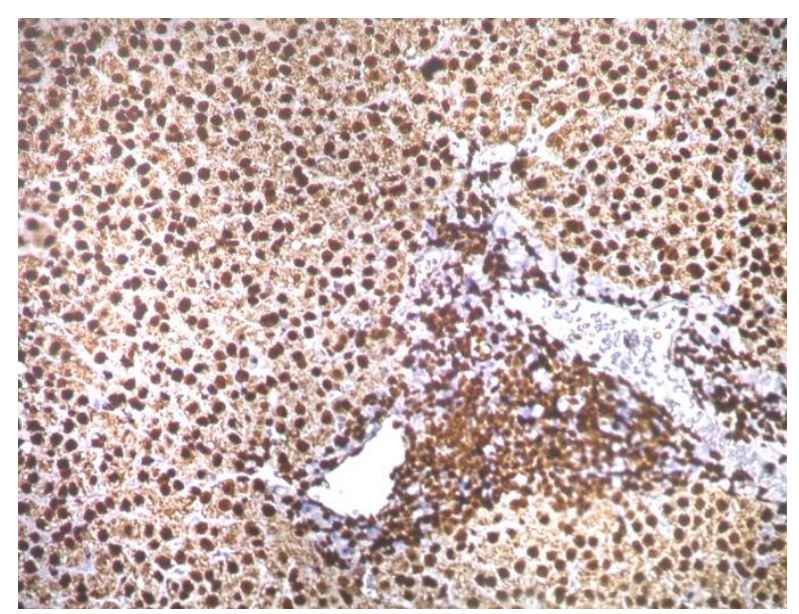

(A)

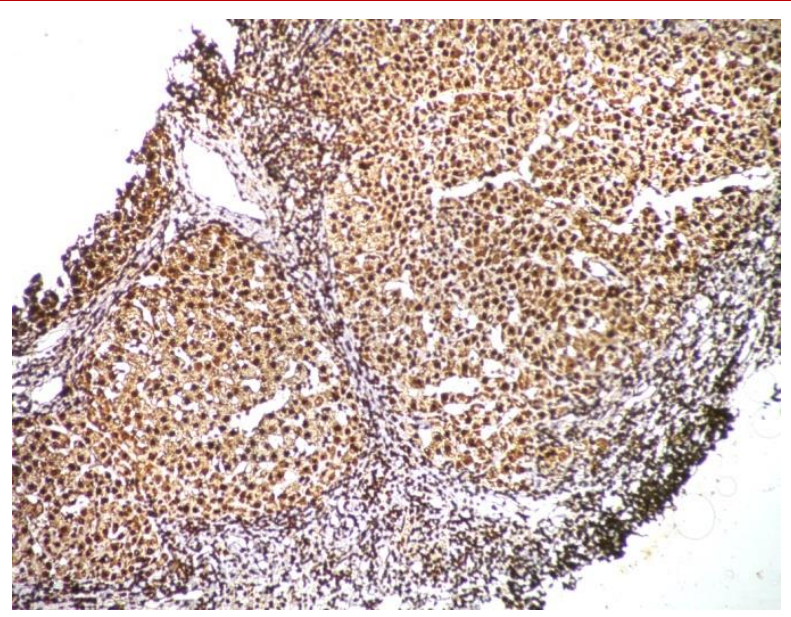

(B)

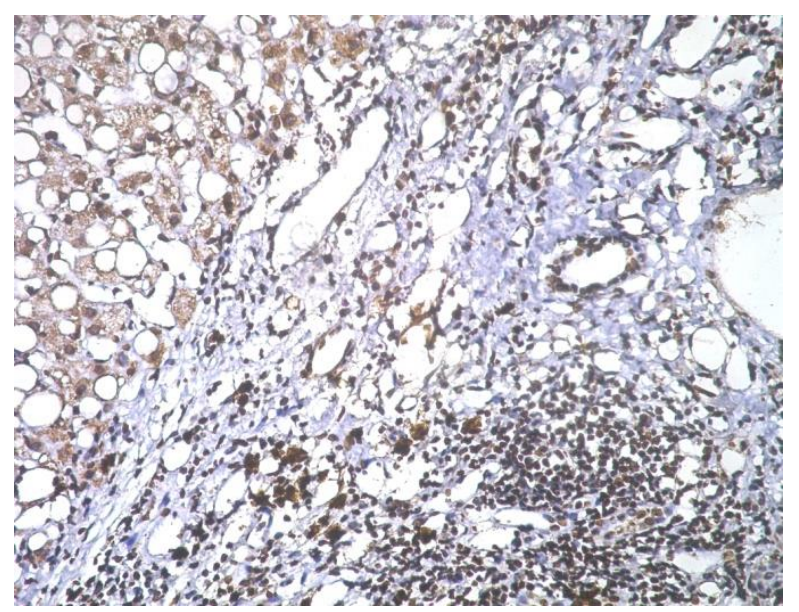

(C)

Fig. 3: 8-OhdG immunoreactivity in chronic hepatitis $\mathrm{C}$ :

A- A core needle biopsy of chronic hepatitis C ( A2, F2) showing high index 8-OhdG nuclear immunoreactivity (Immunoperoxidase stain, X 200 ).

b- A core needle biopsy of chronic hepatitis C ( A2, F3) showing high index 8-OhdG nuclear immunoreactivity (Immunoperoxidase stain, X 200 ).

d- A core needle biopsy of chronic hepatitis C (A3, F4) showing high index 8-OhdG nuclear immunoreactivity, also immunoreactivity of bile duct epithelium and inflammatory cells (Immunoperoxidase stain, X 300 ). 


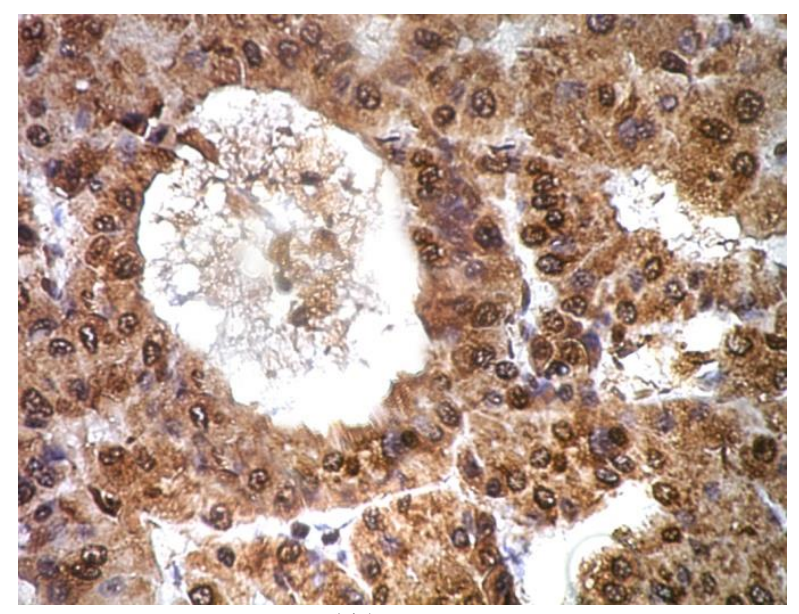

(A)

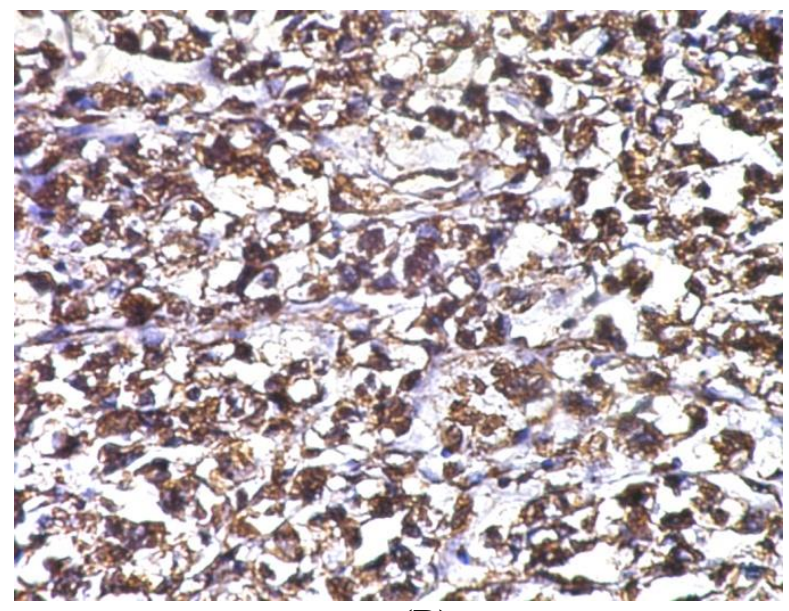

(B)

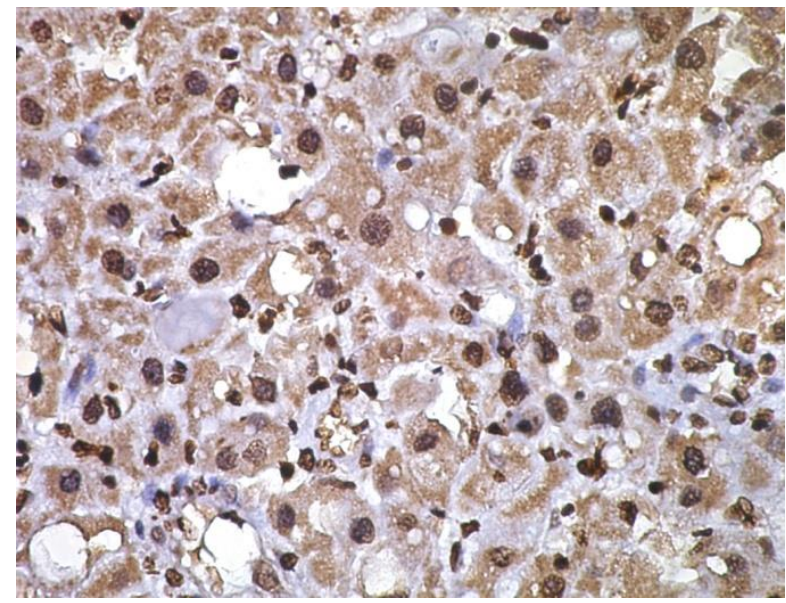

(C)

Fig. 4: 8-OHdG immunoreactivity in hepatocellular carcinoma:

a- Moderately differentiated HCC (acinar pattern) showing high index 8-OHdG nuclear immunoreactivity (Immunoperoxidase stain, X 400 ).

b- Moderately differentiated HCC (clear cell type) showing high index 8-OHdG nuclear immunoreactivity (Immunoperoxidase stain, X 300 ).

c- Poorly differentiated HCC showing high index 8-OHdG nuclear immunoreactivity (Immunoperoxidase stain, X 300 ). 


\section{DISCUSSION}

The present work is a retrospective, cross sectional, study performed on 75 liver paraffin blocks that included 50 cases of chronic hepatitis $\mathrm{C}$ and 25 cases of hepatocellular carcinoma. These cases were collected from the Pathology Department, Faculty of Medicine, Zagazig University, National Cancer Institute in Egypt and liver cancer institute in Menofeya, in the period from October 2012 to January 2014.

The 50 cases of chronic hepatitis $\mathrm{C}$ included 29 cases low grade chronic hepatitis and 21 cases high grade chronic hepatitis, 15 patients had cirrhosis, all in the high-grade group. The 25 cases of hepatocellular carcinoma (HCC) included 9 cases well differentiated HCC (grade I), 11 cases moderately differentiated HCC (grade II) and 5 cases poorly differentiated HCC (grade III). Among 25 cases of HCC, 22 cases showed cirrhosis in the non neoplastic liver tissue.

Glypican-3(GPC-3) belongs to glypican family that is a group of heparin sulfate proteoglycans linked to the outer surface of cell membrane through a glycosyl-phosphatidylinositol anchor [19].

In our study, Glypican-3 was expressed in 9 (18\%) of 50 cases of chronic hepatitis, all of high grade hepatitis $(42.9 \%)$ and non of low grade chronic hepatitis. The staining pattern was exclusively cytoplasmic without staining of plasma membranes or canaliculi, as has been described in some HCCs. There was a statistically significant difference between GPC-3 expression in low and high grade hepatitis $(\mathrm{P}=0.0016)$. This was consistent with Abdul-Al et al. [9] who studied GPC-3 expression in 60 cases of chronic hepatitis $\mathrm{C}$ (30 low grade and 30 high grade)and found that $25(83.3 \%)$ of 30 cases of high grade chronic hepatitis showed positive staining for GPC-3. In contrast, all biopsies in the low-grade group were negative. The positive hepatocytes were present in small groups, usually haphazardly distributed but sometimes with a periportal predominance.

In the present study, glypican-3 was expressed in $13(35.1 \%)$ of 37 cases of cirrhosis, $8 / 22(36.4 \%)$ of cirrhosis with carcinoma and $5 / 15(33.3 \%)$ of cirrhosis without carcinoma. On the other hand, Baumhoer et al. [8] found positivity in 11/95 (12\%) of liver cirrhosis and Shafizadeh et al. [20] found focal positivity in 4 cases of 35 cases of cirrhosis (11\%).

In this work, there was no statistical significant difference in glypican-3 expression between cirrhosis with or without carcinoma $(\mathrm{P}=0.97)$. However, Wang et al. [21] reported that among 67 HCCs with a cirrhotic background, focal GPC-3 immunoreactivity was detected in a small proportion of the cirrhotic nodules in 11 (16.4\%) cases but not in cirrhotic livers without HCC.

Several studies have demonstrated that GPC3 is positive in most $\mathrm{HCC}$, and positive immunostaining has been detected in $52.5 \%$ to $100 \%$ of HCC $[\mathbf{5 , 6}, \mathbf{2 0 , 2 2 , 2 3 ]}$. In the present study, glypican-3 was detected in $22(88 \%)$ of 25 cases of HCC $(77.7 \%$ (7/9) of well differentiated cases, $100 \%$ (11/11) of moderately differentiated cases, and $80 \%(4 / 5)$ of poorly differentiated cases) and there was no statistically significant difference in glypican-3 expression between different grades of HCC. Reactivation of the fetal phenotype, which is common in malignant tumors, may explain the expression of GPC 3 in malignant hepatocellular nodules [24].

$8-\mathrm{OHdG}$ is considered a useful indicator for investigating the involvement of oxidative stress in hepatocarcinogenesis [25]. The expression of 8OHdG have been reported in livers with chronic hepatitis C [26], cirrhosis [27] and carcinoma [28].

In our study,8-OHdG was observed in all cases of chronic hepatitis $\mathrm{C}$, with high labeling index in 41/50(82\%)of cases and low index in $9 / 50(18 \%)$ of cases ,the staining was seen mainly in nuclei of hepatocytes, bile duct cells , portal inflammatory cells, and occasionally in the nuclei of sinusoidal cells.

Similar results were reported by Mahmood et al.[29] who studied the expression of $8-\mathrm{OHdG}$ in eight patients with chronic hepatitis $\mathrm{C}$ and found that $8-\mathrm{OHdG}$ was observed in the nuclei of hepatocytes in all cases and Fujita et al.[30] who found immunoreactivity for $8-\mathrm{OHdG}$ in all 77 $(100 \%)$ of chronic hepatitis $\mathrm{C}$ examined patients.

On the other hand, Sumiyosh et al.[31] observed positive staining for $8-\mathrm{OHdG}$ in $64 \%$ of $\mathrm{HCV}$ patients, Chuma et al.[13] detected expression of $8-\mathrm{OHdG}$ in $62(59.6 \%)$ of 104 patients with chronic hepatitis and Kitada et al.[32] detected $8-\mathrm{OHdG}$ expression in 17 of 24 cases $(70.8 \%)$ with chronic hepatitis $\mathrm{C}$.

In the present study, liver $8-\mathrm{OHdG}$ expression was correlated with hepatic inflammation and there was a statistically significant difference in $8-\mathrm{OHdG}$ expression between low and high grade hepatitis $(\mathrm{P}=0.05)$, this was consistent with Fujita et al.[33] who found that $8-\mathrm{OHdG}$ expression was correlated with the grade of hepatitis $(\mathrm{P}=0.032)$, this correlation may indicate the direct involvement of hepatic oxidative stress in the pathogenesis and 
progression of liver cell injury in chronic viral hepatitis.

This correlation with the grade of hepatitis was also consistent with the results of Chuma et al.[13] and Kitada et al.[32]who reported that 8OHdG was correlated with the grade of hepatitis but in contrast to Fukushima et al.[34] who found that the number of 8-OHdG-positive cells was not correlated with hepatic inflammatory activity grade.

Our study showed high labeling index of 8OHdG in $13 / 25(52 \%)$ of cases of HCC and low index in $12 / 25(68 \%)$ of cases, and there was no statistically significant difference between grades, this positivity for $8-\mathrm{OHdG}$ in $\mathrm{HCC}$ was also reported by Ichiba et al.[28] and Jo et al.[35]who observed 8-OHdG positivity in $25(83 \%)$ of the 30 HCC cases and $56.4 \%$ of their examined HCC cases, resprctively.

In this work, there was a statistically significant difference in $8-\mathrm{OHdG}$ expression between HCC and chronic hepatitis C $(\mathrm{P}=0.006)$, this was consistent with Fukushima et al., [34] who compared the expression levels of $8-\mathrm{OHdG}$ in non-tumor liver tissue of HCC patients without diagnosed disease predisposing to those of HCC patients with chronic hepatitis $\mathrm{C}$ and found a significant higher expression level in those with $\mathrm{HCV}$.

Our results also similar to Schwartz et al.[25] who demonstrated increased 8-OHdG concentrations in non tumorous tissue of $\mathrm{HCC}$ patients compared to tumorous tissue.

Previous reports have noted the high expression of $8-\mathrm{OHdG}$ in the livers of chronic viral hepatitis patients $[\mathbf{2 8 , 3 2}$, and our results are consistent with these reports. Recent studies have shown that high expression of $8-\mathrm{OHdG}$ in livers with $\mathrm{CHV}$ predicted the development of primary HCC $[13,14]$ and also postoperative recurrence $[36,37]$, suggesting the association of $8-\mathrm{OHdG}$ and carcinogenesis in livers with chronic viral hepatitis C. Our results demonstrated that oxidative DNA damage widely occurs in the liver with chronic liver injury suggesting a possible link between active inflammation and hepatocarcinogenesis.

The presence of oxidative stress markers in HCC tissue as well as in non-HCC tissue indicates that oxidative stress is closely related to the development of HCC and that non-HCC tissue under oxidative stress may become carcinomatous in the future. The importance of detection of OS markers and antioxidant therapy in $\mathrm{HCV}$-associated liver disease is to slow down disease progression and HCC occurrence [29].

\section{CONCLUSION}

Glypican-3 was expressed in 18\% of cases of chronic hepatitis C, $35.1 \%$ of cirrhosis and $36.4 \%$ of cirrhosis adjacent to carcinoma. Our results suggest that GPC-3 may be considered as an early marker of liver carcinogenesis. 8-OHdG was observed in all cases of chronic hepatitis $\mathrm{C}$, with high labeling index in $82 \%$ of cases and low index in $18 \%$ of cases. Our study showed high labeling index of $8-\mathrm{OHdG}$ in $52 \%$ of cases of HCC. These results indicate that oxidative DNA damage is common in chronic liver disease suggesting a possible link between chronic inflammation and hepatocarcinogenesis. Early detection, continuous monitoring, and subsequent treatment of OS in HCV-related liver disease may prevent further liver damage and slow down or prevent HCC development.

\section{REFERENCES}

1. Ferlay J, Shin HR, Bray F, et al. GLOBOCAN 2008: Cancer Incidence and Mortality Worldwide: IARC CancerBase No. 10 [Internet]. Lyon, France: International Agency for Research on Cancer. Available from: http://globocan.iarc.fr; 2010.

2. Shaker MK, Abdella HM, Khalifa MO, El Dorr AK: Epidemiological characteristics of hepatocellular carcinoma in Egypt: a retrospective analysis of 1313 cases Liver International 2013; 33 (Issue 10): 1601-1606.

3. Saad Y, El-Serafy M, Eldin M, Abdellatif Z, Khatab H, Elbaz T, Elgarem H: New Genetic Markers for Diagnosis of Hepatitis C Related Hepatocellular Carcinoma in Egyptian Patients.J Gastrointestin Liver Dis 2013; 22 (4): 419-425.

4. Dhanasekaran R, Limaye A and Cabrera R: Hepatocellular carcinoma: current trends in worldwide epidemiology, risk factors, diagnosis, and therapeutics Hepatic Medicine: Evidence and Research 2012; 4: 19-37

5. Yan B, Wei JJ, Qian YM, Zhao XL, Zhang WW, et al.: Expression and clinicopathologic significance of glypican 3 in hepatocellular carcinoma. Ann Diagn Pathol 2011; 15: 162-169.

6. Tatrai P, Somoracz A, Batmunkh E, et al.: Agrin and CD34 immunohistochemistry for the discrimination of benign versus malignant hepatocellular lesions. Am J Surg Pathol 2009; 33: 874-85.

7. Anatelli F, Chuang ST, Yang XJ, Wang HL: Value of glypican 3 immunostaining in the diagnosis of hepatocellular carcinoma on needle biopsy. Am J Clin Pathol 2008;130: 219-23.

8. Baumhoer D, Tornillo L, Stadlmann S, Roncalli M, Diamantis E and Terracciano L: Glypican 3 Expression in Human Nonneoplastic, Preneoplastic, and Neoplastic Tissues.A Tissue Microarray Analysis of 4,387 Tissue Samples . Am J Clin Pathol 2008;129: 899-906. 
9. Abdul-Al H, Makhlouf H, Wang G, Goodman Z: Glypican-3 expression in benign liver tissue with active hepatitis $\mathrm{C}$ : implications for the diagnosis of hepatocellular carcinoma. Human Pathology 2008; 39: 209-212.

10. Kasai H: Analysis of a form of oxidative DNA damage, 8-hydroxy-20-deoxyguanosine, as a marker of cellular oxidative stress during carcinogenesis. Mutat Res 1997; 387: 147-163.

11. Karihtala P, Soini Y: Reactive oxygen species and antioxidant mechanisms in human tissues and their relation to malignancies. APMIS 2007; 115: 81-103.

12. Fujita N, Horiike S, Sugimoto R, Tanaka H, IwasaM, Kobayashi $\mathrm{Y}$, Hasegawa $\mathrm{K}$, Ma N, Kawanishi S, Adachi Y, Kaito M: Hepatic oxidative DNA damage correlates with iron overload in chronic hepatitis $\mathrm{C}$ patients. Free Radic Biol Med 2007; 42: 353-562.

13. Chuma M, Hige S, Nakanishi $M$, et al.: 8Hydroxy-2'-deoxy-guanosine is a risk factor for development of hepatocellular carcinoma in patients with chronic hepatitis $\mathrm{C}$ virus infection. $\mathrm{J}$ Gastroenterol Hepatol 2008; 23: 1431-1436.

14. Tanaka H, Fujita N, Sugimoto R, Urawa N, Horiike S, Kobayashi Y, Iwasa M, Ma N, Kawanishi S, Watanabe S, Kaito M, Takei Y: Hepatic oxidative DNA damage is associated with increased risk for hepatocellular carcinoma in chronic hepatitis C. Br J Cancer 2008; 98: 580586.

15. Li S, Wang X, Wu Y, Zhang H, Zhang L, Wang C, Zhang $\mathrm{R}$ and Guo Z: 8-Hydroxy-2'deoxyguanosine expression predicts hepatocellular carcinoma outcome Oncology Letters 2012; 3: 338-342.

16. Bedossa P, Poynard T, for the METAVIR Cooperative Study Group. An algorithm for the grading of activity in chronic hepatitis C. Hepatology.1996; 24: 289-293.

17. Hamilton SR, Aaltonen LA, eds. World Health Organization (WHO) classification tumours of the digestive system. Lyon, France: IARC Press, 2000:158-172

18. Gong L, Wei L, Ren P, Zhang W, Liu X, Han X, Yao L, Zhu S, Miao Lan M, Li Y, Zhang W: Dysplastic Nodules with Glypican-3 Positive Immunostaining: A Risk for Early Hepatocellular Carcinoma PLoS ONE 2014; 9(1): e87120.

19. Filmus J, Capurro M, Rast J. Glypicans. Genome Biol 2008; 9: 224.

20. Shafizadeh N, Ferrell L, Kakar S: Utility and limitations of glypican-3 expression for the diagnosis of hepatocellular carcinoma at both ends of the spectrum. Mod Pathol 2008; 21: 10111018.

21. Wang H, Anatelli F, Zhai Q, Adley B, Chuang S, Yang X: Glypican-3 as a Useful Diagnostic Marker That Distinguishes Hepatocellular Carcinoma From Benign Hepatocellular Mass Lesions. Arch Pathol Lab Med 2008;132: 17231728 .
22. Su N, Chen B, Huang N, Shen P, Ding Y, et al.:Glypican-3, a novel prognostic marker of hepatocellular cancer, is related with postoperative metastasis and recurrence in hepatocellular cancer patients. Mol Biol Rep 2011; 15: 162-169.

23. Ligato S, Mandich D, Cartun RW. Utility of glypican-3 in differentiating hepatocellular carcinoma from other primary and metastatic lesions in FNA of the liver: an immunocytochemical study. Mod Pathol 2008; 21: 626-31.

24. Wang XY, Degos F, Dubois S, Tessiore S, Allegretta M, Guttmann RD, et al.: Glypican-3 expression in hepatocellular tumors: diagnostic value for preneoplastic lesions and hepatocellular carcinomas. Hum Pathol 2006; 37: 1435-41.

25. Schwarz KB,Kew M, Klein A, et al.: Increased hepatic oxidative DNA damage in patients with hepatocellular carcinoma. Dig Dis Sci 2001; 46: 2173-8.

26. Horiike S, Kawanishi S, Kaito $\mathrm{K}$, et al. Accumulation of 8-nitroguanine in the liver of patients with chronic hepatitis C. J Hepatol 2005; 43: 403-10.

27. Marotta F, Yoshida C, Barreto R, Packer L: Oxidativ-inflammatory damage in cirrhosis:effects of vitamin $\mathrm{E}$ and a fermented papaya preparation. J Gastroenterol Hepatol 2007; 22: 697-703.

28. Ichiba $\mathrm{M}$, Maeta $\mathrm{Y}$, Mukoyama $\mathrm{T}$, et al: Expression of 8-hydroxy-2'-deoxyguanosine in chronic liver disease and hepatocellular carcinoma. Liver Int 2003; 23: 338-345.

29. Mahmood S, Kawanaka M, Kamei A, Izumi A, Nakata K, Niiyama G, Ikeda H, Hanano S, Suehiro M, Togawa K, Yamada G: Immunohistochemical evaluation of oxidative stress markers in chronic hepatitis C. Antioxid Redox Signal 2004; 6: 19-24.

30. Fujita N, Horiike S, Sugimoto R, Tanaka H, IwasaM, Kobayashi Y, Hasegawa K, Ma N, Kawanishi S, Adachi Y, Kaito M: Hepatic oxidative DNA damage correlates with iron overload in chronic hepatitis $\mathrm{C}$ patients. Free Radic Biol Med 2007; 42: 353-562.

31. Sumiyoshi S, Kobayashi Y, Kawamura K, Kawata K, Nakamura H: Differential expression of hepatic apurinic/apyrimidinic endonuclease 1, a DNA repair enzyme, in chronic hepatitis World J Hepatol 2013 April 27; 5(4): 206-213.

32. Kitada T, Seki S, Iwai S, Yamada T, Sakaguchi H and Wakasa K: In situ detection of oxidative DNAdamage, 8-hydroxydeoxyguanosine, in chronic human liver disease. J Hepatol 2001; 35: 613-618.

33. Fujita N, Sugimoto R, Ma N, Tanaka H, Iwasa M, Kobayashi Y, Kawanishi S, Watanabe S, Kaito M, Takei Y: Comparison of hepatic oxidative DNA damage in patients with chronic hepatitis B and C. J Viral Hepat 2008; 15: 498-507. 
34. Fukushima N,Kuromatsu, Akiba J,Andoo E, Takata A, SumiebS, Nakano M, Nakamura T, Kawahara A, et al. 2010: Characteristic expression pattern of oxidative stress in livers with cryptogenic hepatocellular carcinoma Experimental and Therapeutic Medicine 1: 809816.

35. Jo M, Nishikawa $T$, Nakajima $T$, Okada $Y$, Yamaguchi K Mitsuyoshi H, Yasui K, Minami M, et al.: Oxidative stress is closely associated with tumor angiogenesis of hepatocellular carcinoma. J Gastroenterol 2011; 46: 809-821.
36. Maki A, Kono H, Gupta M, Asakawa M, Suzuki T, Matsuda M, Fujii H, Rusyn I: Predictive power of biomarkers of oxidative stress and inflammation in patients with hepatitis $\mathrm{C}$ virusassociated hepatocellular carcinoma. Ann Surg Oncol 2007; 14: 1182-1190.

37. Matsumoto K, Satoh Y, Sugo H, et al: Immunohistochemical study of the relationship between 8-hydroxy-2'-deoxyguanosine levels in noncancerous region and postoperative recurrence of hepatocellular carcinoma in remnant liver. Hepatol Res 2003; 25: 435-441. 
الملخص العربي

خلفية: في مصر،سرطان الخلايا الكبدية هو ثاني أكثر أنواع السرطان شيو عالدى الرجال وسادس أكثر أنواع السرطان شيو عا عند النساء.

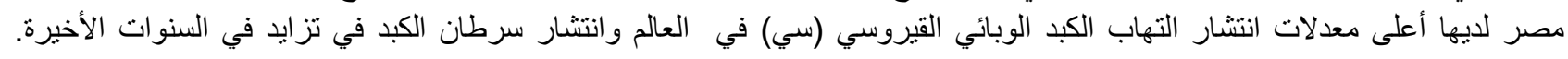

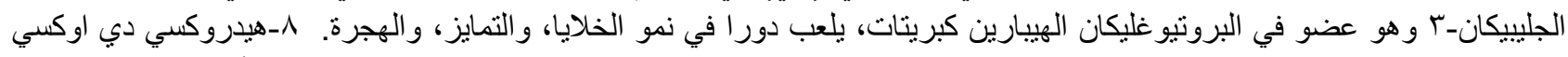

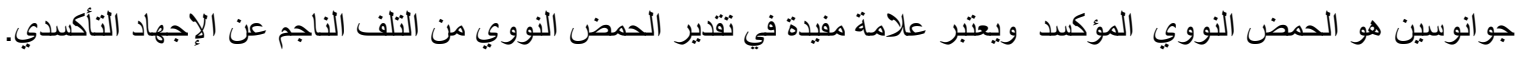

الهـف: أجريت هذه الدراسة لتقييم اظهار الجلييكان-؟ و ^-هيدروكسي دي اوكسي جوانوسين في التهاب الكبد الوبائي الفيروسي المزمن (سي) وسرطان خلايا الكبد كعلامات تتبؤية لسرطان الكبد.

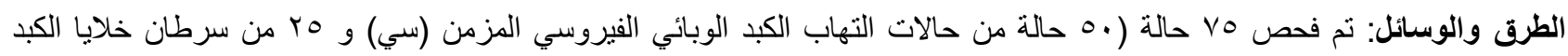

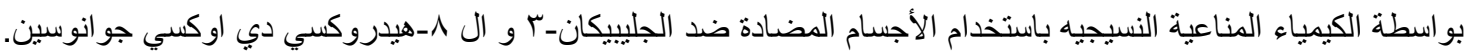

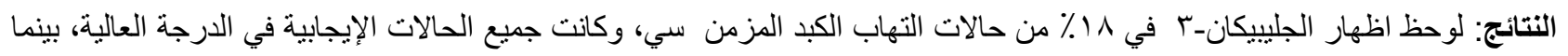

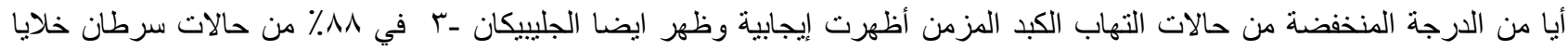

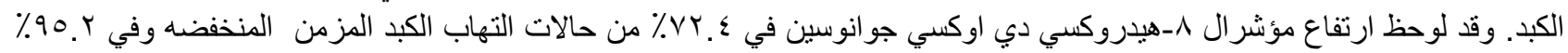

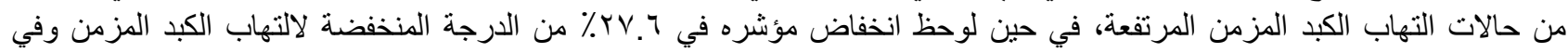

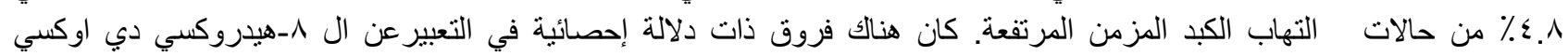

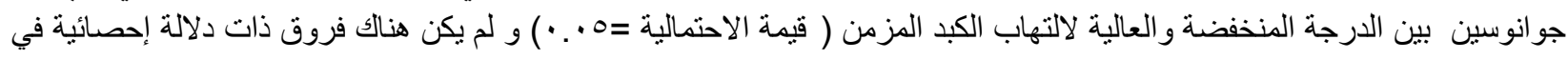

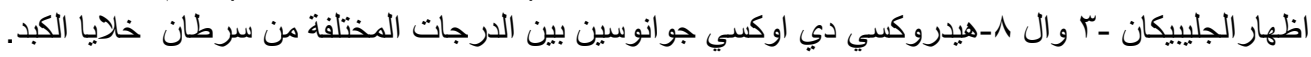

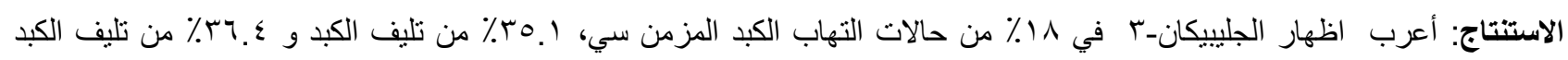

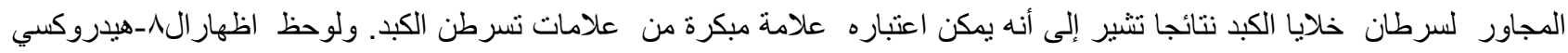

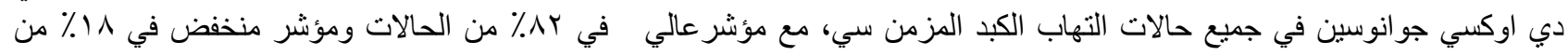

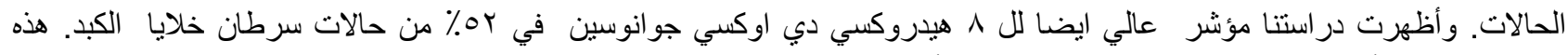

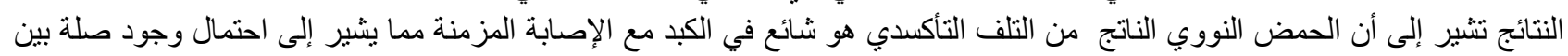
الالتهاب الكبدي المزمن و الإصابة بأورام الكبد السرطانية. 